\title{
Management of potential drug interactions in community pharmacies: a questionnaire-based survey in Switzerland
}

\author{
Jörg Indermitte • Laura Erba • Marianne Beutler • \\ Rudolf Bruppacher • Walter E. Haefeli • \\ Kurt E. Hersberger
}

Received: 5 July 2006 / Accepted: 15 November 2006 / Published online: 11 January 2007

(C) Springer-Verlag 2007

\begin{abstract}
Objective To analyze the current drug-interaction management in Swiss community pharmacies, with a particular focus on electronic systems, and to compare the results with those expressed by German general practitioners in a recent survey.

Methods Data were collected with a postal questionnaire which was randomly sent to 500 out of 833 community pharmacies in the German part of Switzerland.

Results The response rate was $57.4 \%$, and only $24.7 \%$ pharmacists reported that they were confronted less than daily with potential drug interactions. Use of computer software to identify potential drug interactions was widespread in community pharmacies $(90.2 \%)$, and the software was the primary source of information $(81.2 \pm 29.6 \%)$. The quality of the interaction software was judged sensitive (identifying all dangerous interactions) by $80.5 \pm 21.5 \%$, but
\end{abstract}

J. Indermitte $\cdot$ L. Erba $\cdot$ K. E. Hersberger $(\bowtie)$

Department of Pharmaceutical Sciences, Institute of Clinical

Pharmacy, University of Basel, Pharmazentrum (0059),

Klingelbergstrasse 50 ,

CH-4056 Basel, Switzerland

e-mail: Kurt.Hersberger@unibas.ch

M. Beutler $\cdot$ K. E. Hersberger

Medicines Commission of Swiss Pharmacists,

Bern, Switzerland

\section{R. Bruppacher}

Institute of Social and Preventive Medicine, University of Basel,

Basel, Switzerland

W. E. Haefeli

Department of Internal Medicine VI, Clinical Pharmacology and Pharmacoepidemiology, University of Heidelberg,

Heidelberg, Germany specific (identifying only relevant interactions) by only $38.3 \pm 32 \%$. Pharmacists declared a low override rate $(14 \%)$ of drug interaction alerts, although unjustified alerts were reported by $60.6 \pm 33.1 \%$. In contrast to general practitioners, pharmacists opted less often for information on the mechanism of the interaction, and more frequently for details for dose adjustment. Both groups complained about deficient information on non-interacting alternatives.

Conclusion The information needs of community pharmacists differed considerably from general practitioners, and pharmacists were overwhelmed by inappropriate alerts because of a lack of specificity of their drug-interaction systems. Substantial improvement of drug-interaction software systems is thus required at least in two important aspects, the suppression of inappropriate alerts and the tailoring to the needs of the user.

Keywords Community pharmacist · Drug interaction . Pharmacotherapy $\cdot$ Information technology

\section{Introduction}

Potential drug interactions are highly prevalent, but the number of adverse drug reactions caused by drug interactions is probably low [1-4]. Reported incidences in outpatients range from $9.2 \%$ to $70.3 \%$ for drug interactions of any severity, and from $1.2 \%$ to $23.3 \%$ for those considered of major relevance [5-11]. A German primarycare study showed that of all observed major or moderate potential drug interactions only $11.7 \%$ offered no management options, and such drug combinations should thus be avoided [12]. The majority of the potential drug interactions do not result in clinical manifestations if they are managed 
adequately, e.g. by dose adjustment or a coordinated sequence of administration [12]. However, given the frequency of combination treatment, even a low penetrance of complications caused by drug interactions will substantially impact drug safety. Indeed drug interactions are responsible for up to $3.8 \%$ of hospital admissions [2, 13-15].

In some countries, including Switzerland, community pharmacies are obliged to keep a medication history of all dispensed prescription drugs and to check prescriptions, to prevent the use of unsafe drug regimens including those caused by potentially interacting drugs. To comply with these statutory requirements, almost all pharmacies use computer software systems for the quality assurance of pharmacotherapy. These systems identify potential drug interactions, alert the pharmacy team to intervene before dispensing potentially interacting drugs, and serve as a drug-interaction information source.

Thus far, only very few epidemiologic studies on the adverse outcomes of drug interactions have been performed. Therefore, drug-interaction information sources generally lack data on clinical importance of potential drug interactions and information on risk factors that contribute to their adverse outcomes. Indeed, the majority of general practitioners were dissatisfied with the information on therapeutic alternatives, severity, mechanism, and dose adjustment in the drug-interaction information sources they used [16]. Consequently electronic drug-interaction information sources should include management guidelines for dose adjustment and spacing of administration times, and should help to avoid contraindicated drug combinations. Moreover, they should also provide monitoring information for an early detection of adverse events.

Drug-interaction information is required on different levels of drug therapy. First, the prescription of drug combinations should be supported by appropriate information technology to maintain high quality standards already at the point of care. In addition to the support of physicians in drug selection and dosing, the dispensing pharmacies should also have access to comprehensive information on drug interactions, in order to assess combinations prescribed by several independent physicians in charge of a patient, and also to detect risks arising from combinations with drugs dispensed without prescription. Obviously, safety concerns detected in a pharmacy should be resolved in communication with the treating physician, who ideally has access to the same knowledge bases. Because pharmacists and physicians have different duties in pharmacotherapy, and also different training, their information needs may also differ. We therefore aimed to assess how pharmacists deal with drug interactions in daily practice, which information sources they use and wish to have, and how their requirements relate to those expressed by general practitioners.

\section{Methods}

\section{Study population}

From the 833 pharmacies in the German speaking part of Switzerland, a random sample of 500 community pharmacies was invited to participate in this cross-sectional survey. Pharmacies were selected by use of the freeware Research Randomizer (http://www.randomizer.org/form.htm). No stratification or any other selection procedures were applied.

In Switzerland, community pharmacies dispense $68.9 \%$ of all over-the-counter drugs, and $57.2 \%$ of all prescription drugs. The remaining drugs are dispensed by physicians (27.8\%), hospitals (13.9\%), and drug stores (1.2\%) [17]. If not limited by regional legislation, physicians are allowed to store drugs in their practice and dispense drugs to their patients.

All Swiss community pharmacies have electronic drug management systems. The knowledge base on drug interactions integrated in these systems was originally developed by ABDATA (Eschborn, Germany) [18] to be used in all Austrian, German, and Swiss community pharmacies. The knowledge base is adapted by E-mediat AG (Schönbühl, Switzerland) to the Swiss market and sold to pharmacy software providers. Furthermore, it is published as an integrated part of Pharmavista [19], a drug information service which is available on the Internet or on CD-ROM as a subscription-only service for Swiss health care professionals. Each drug-interaction monograph is fully referenced and updated on a monthly basis. Potential drug interactions are classified into "severe" (life-threat / intoxication / permanent harm), "moderate" (frequent therapeutic problems / combination can be administered but close monitoring required), "minor" (increased or decreased drug effect / only specific subgroups affected), "negligible" (no or limited clinical effects / generally no modification of therapy required) and "external specifications" (only occurring in particular cases / clinical consequences unclear). The majority of electronic drug-interaction systems used in Swiss community pharmacies can be set up to flag only potential drug interactions of moderate and/or high severity. Such alerts can either be "ignored" (overridden); "considered" (deliberate response to the alert), or in some cases have to be "analysed" more precisely through consideration of additional parameters (e.g. patient-related risk factors) and consultation of drug-interaction information sources.

Data collection

The questionnaire included 28 items grouped in four sections. The first part of the questionnaire contained three 
questions to clarify pharmacists' perceptions of drug interactions and the preoccupation with this problem in daily practice. The second part focused on management of interaction alerts in pharmacy practice, with three questions on the configuration of the drug-interaction surveillance software, three questions on the capability of their druginteraction surveillance software to be "sensitive" (software identifies $\%$ of cases of dangerous potential drug interactions) and to be "specific" (software identifies \% of cases of really clinically relevant potential drug interactions) and to flag "false" alerts (e.g. multiple or repeated alerts for the same patient, the patient was no longer taking the interacting drug, in \% of cases), and four questions on the actions taken by pharmacy teams after drug-interaction alerts. A third part contained five questions on the usage (frequency and type) of drug-interaction information sources and the pharmacists' satisfaction with the provided information. Eight questions in the fourth part addressed the communication with physicians. Additionally, characteristics of the pharmacists (gender, professional experience, working hours, postgraduate education) and their community pharmacies (location, profile of customers, and implementation of quality management system) were assessed. We used multiple choice questions or visual analogue scales ranging from "never" (coded as $0 \%$ ) to "always" (coded as 100\%).

Questions on pharmacists' perception of the risk arising from potential drug interactions, the preoccupation with potential drug interactions in daily practice, the usage (frequency and type) of drug-interaction information sources, and their satisfaction with the information provided were retrieved from a recent structured questionnairebased survey among German general practitioners [16].

The study was carried out between June 2005 and August 2005. The questionnaire was sent together with a letter explaining the rationale of the study and a prestamped return envelope. Questionnaires had to be filled in by the pharmacy manager or his substitute. Comprehensibility of the questionnaire was evaluated in a pretest among ten community pharmacists. To increase the response rate, responders could win one of five annual subscriptions to an educational community pharmacy drug information service (value $=40$ EUR). Four weeks later, a reminder was sent together with a second questionnaire to non-responders of the survey to further boost response rates [20]. To characterize non-responders, gender, age, professional experience, configuration of the drug-interaction surveillance software settings, and reason for non-response were assessed in a telephone interview with 50 randomly selected non-responding pharmacy managers.

All returned questionnaires were processed with the automated forms processing software Teleform version 7.0 from Cardiff Software Inc., Vista, CA, USA. Automated forms processing software was validated by Jorgensen et al. [21] who showed an improved quality of the data while reducing the processing time. To avoid potential errors, all numeric and letter recognitions were verified visually on data sheets and on screen.

\section{Data analysis}

Results are expressed as proportions and as means \pm standard deviation (SD) or medians with the $25 \%$ to $75 \%$ interquartile range (IQR). Main descriptive results are expressed as absolute numbers and percentages. Independent two-sample comparison of single variables was analysed using student's $t$-test. Chi-square statistics were used for categorical comparisons. In a multiple logistic regression analysis, the daily preoccupation with potential drug interactions or the frequency of using drug-interaction information sources as dependent variables were dichotomised into "daily" (for each prescription, several times daily, daily) versus all other categories (once a week, once a month, less than once a month, never). Covariates were gender, professional experience, working hours [\%], pharmacy certified for quality management, pharmacy location in countryside or village, predominantly changing customers, postgraduate education as community pharmacist, the pharmacies' software configuration to flag only "severe" potential drug interactions, and software configuration of the length of the period a patient's past medication history was screened for potential drug interactions. Odds ratios (OR) are presented with $95 \%$ confidence intervals (CI). Statistical significance was defined as a $p$-value $<0.05$. All statistical analyses were performed using SPSS for Windows version 13.0 (SPSS, Inc, Chicago, IL, USA).

\section{Results}

Characteristics of the study sample

Of 500 invited community pharmacies, $57.4 \%$ (287) returned the questionnaire. Most questionnaires $(87.1 \%$, $250 / 287$ ) were filled in by the pharmacy manager. More than $95 \%$ of the questions were answered by all responders. Characteristics of the responding pharmacists and their community pharmacies are presented in Table 1. Comparison of responding pharmacy managers with 50 nonresponding pharmacy managers showed no significant differences with respect to gender $(p=0.54)$, mean age $(p=0.56)$, professional experience $(p=0.47)$, and the location of their community pharmacies $(p=0.36)$. The main 
Table 1 Characteristics of the participating pharmacists and their pharmacies

\begin{tabular}{|c|c|c|}
\hline $\begin{array}{l}\text { Characteristics of } \\
\text { responding pharmacists }\end{array}$ & $N^{*}(100 \%)$ & \\
\hline Mean age \pm SD [years] & 283 & $45.0 \pm 9.4$ \\
\hline Female gender & 286 & $157(54.9 \%)$ \\
\hline $\begin{array}{l}\text { Mean years of professional } \\
\text { experience } \pm \text { SD [years] }\end{array}$ & 283 & $18.5 \pm 9.5$ \\
\hline Mean working time $\pm \mathrm{SD}$ & 282 & $90 \% \pm 15 \%$ \\
\hline Pharmacy manager & 284 & $250(88.0 \%)$ \\
\hline $\begin{array}{l}\text { Postgraduate specialisation } \\
\text { as community pharmacist }\end{array}$ & 285 & $215(75.4 \%)$ \\
\hline $\begin{array}{l}\text { Characteristics of community } \\
\text { pharmacies }\end{array}$ & $N^{*}(100 \%)$ & \\
\hline Location & 286 & \\
\hline City or urban agglomeration & & $200(69.9 \%)$ \\
\hline Countryside or village & & $86(30.1 \%)$ \\
\hline $\begin{array}{l}\text { Predominantly regular customers } \\
\text { (versus changing customers) }\end{array}$ & 285 & $212(74.4 \%)$ \\
\hline $\begin{array}{l}\text { Implementation of quality } \\
\text { management system }\end{array}$ & 286 & \\
\hline Implemented & & $27(9.5 \%)$ \\
\hline Submitted for certification & & $83(29.0 \%)$ \\
\hline No quality management system & & $176(61.5 \%)$ \\
\hline
\end{tabular}

* Number of 287 pharmacists responding to individual question

reasons for non-response were lack of time or interest (34\%) and personal absence during the survey period $(26 \%)$.

Perception of the risk arising from drug interactions and preoccupation with potential drug interactions

For the majority of the responding pharmacists [91\% (261/ 287)] drug interactions were an important safety hazard in pharmacotherapy. Of these, $19.5 \%$ (51/261) judged the clinical relevance of drug interactions to be an outstanding problem, 76.2\% (199/261) to be equally important, and only $4.2 \%$ (11) to be subordinate compared with other safety hazards in pharmacotherapy. Neither a significant association with gender or postgraduate specialisation in community pharmacy nor a trend with age, workload, or years of professional experience was found $(p>0.05)$. The majority $(75.3 \% ; 216 / 287)$ of the responding pharmacists mentioned the fact that they dealt at least daily with potential drug interactions.

Configuration and perception of the quality of drug interaction surveillance software

The community pharmacies' computers were equipped with pharmacy software from six different providers, and most of them $(90.2 \% ; 259 / 287)$ used their software to identify potential drug interactions. In contrast, 9.8\% (28/287) had inactivated this option in their computer system. Those pharmacies were less frequently certified with a quality management system $(p=0.032)$ and felt less frequently confronted with potential drug interactions $(p<0.001)$. In $18.5 \%$ (48/259) of the community pharmacies, the drug interaction surveillance software was set to flag only "severe", in 39.8\% (103/259) to flag "severe" and "moderate", and in $41.7 \%(108 / 259)$ to flag all potential drug interactions. In pharmacies in which the software was set to flag only "severe" potential drug interactions, pharmacists dealt less frequently with potential drug interactions $(p<0.001)$. The median length of the period a patient's past medication history was screened for potential drug interactions was 120 days (IQR 90-180 days). Pharmacists estimated the quality of their drug interaction surveillance software to be "sensitive" in $80.5 \pm 21.5 \%$, to be "specific" in $38.3 \pm 32 \%$, and to flag "false" alerts (e.g. multiple or repeated alerts for the same patient, the patient was no longer taking the interacting drug) in $60.6 \pm 33.1 \%$ of druginteraction alerts. If the software was set to flag only "severe" potential drug interactions, pharmacists $(n=259)$ rated their drug interaction surveillance software to be less "sensitive" (72.1 $\pm 27.0 \%$ vs $82.6 \pm 19.5 \% ; p=0.018)$ but more "specific" $(54.7 \pm 36.7 \%$ vs $34.8 \pm 29.8 \% ; p=0.002)$. When pharmacists estimated that the software produced "false" alerts in $\geq 50 \%$ ( $n=169)$ of alerts, their software was configured to observe a significantly longer period of the medication history (170.5 \pm 97.8 days vs $133.1 \pm 82.3$ days; $p=0.007)$. Multiple logistic regression analysis confirmed these results: configuration of the pharmacy software to flag only "severe" potential drug interactions (OR 0.009, 95\% CI $0.003,0.028 ; p<0.001)$, and the configuration of the length of the period a patient's past medication history was screened for potential drug interactions (OR 1.014, 95\% CI 1.003, 1.025; $p=0.014$ ) were associated with the daily preoccupation with potential drug interactions, while no effect was observed with all other defined covariates (see Methods).

Management of drug interaction alerts by community pharmacy teams

Written directives for the management of flagged druginteraction alerts were available in $18.5 \%$ (48/259) of the community pharmacies, while $78.4 \%$ (203/259) reported that they had only verbal instructions. Pharmacists estimated that drug-interaction alerts are always "considered" in $86 \pm$ $18.6 \%$ of cases by their pharmacy teams. This proportion was not higher if the drug-interaction surveillance software was configured to flag only "severe" potential drug interactions $(p=0.19)$. Pharmacists estimated that a more thorough follow-up "analysis" of drug interaction alerts through consultation of further information sources was 
required in $63.8 \pm 32.7 \%$ of the alerts. This frequency was higher if the drug interaction surveillance software was configured to flag only "severe" potential drug interactions $(p<0.001)$.

Of all community pharmacies, 79.8\% (229/287) documented activities triggered by the detection of potential drug interactions. Of them, 36.2\% (83/229) stated that they documented their activities only if a "severe" potential drug interaction was flagged, 20.1\% (46/229) only if a physician was contacted, 30.1\% (69/229) only if the therapy was modified (e.g. closer monitoring, dose adjustment, or alternative therapy), and $11.8 \%(27 / 229)$ in any situation. Furthermore, pharmacists estimated that in their pharmacies $70.8 \pm 28.1 \%$ of the customers are informed about potentially interacting drugs.

Perception of use and quality of drug interaction information sources

In the case of consultation of drug-interaction information sources to analyse an alert more precisely or to answer a specific question, pharmacists indicated that they favoured drug-interaction information provided by their electronic drug interaction system in $81.2 \pm 29.6 \%$, and the published national drug formulary [22] in $67.2 \pm 32 \%$ of the cases. More male pharmacists reported to use preferentially (i.e. in $\geq 50 \%$ of cases) electronic drug-interaction information sources (community pharmacies' drug-interaction surveillance software, the drug interaction knowledge base of Pharmavista [19], or further specific electronic drug interaction information sources available via internet or from their local computer or personal digital assistant software (e.g. DRUGREAX Thompson Micromedex, Greenwood Village or Stockley's Drug Interactions, Electronic Version 2006 The Pharmaceutical Press, London, etc.) $(p=0.05)$. In general, $70.3 \%$ of the pharmacists $(199 /$ 283) reported that they use their drug interaction information sources "daily".

Multiple logistic regression analysis did not show an association between the "daily" use of drug-interaction information sources and defined covariates (see methods).

Figures 1 and 2 show satisfaction with the content provided by the drug-interaction information sources currently used and the expectations with respect to the content of future drug-interaction information sources. The use of the same questions asked in a recent survey in general practitioners [16] enabled direct comparison of responses of community pharmacists with those of general practitioners. Congruently, community pharmacists and general practitioners were most dissatisfied with the content of their drug-interaction sources concerning non-interacting alternative therapies. Both equally considered the severity
Fig. 1 Swiss pharmacists' and German general practitioners' satisfaction with the content provided by the drug-interaction information sources they currently use. Comparison of the results of two questionnaire surveys in 287 pharmacists and 1216 general practitioners. $N=$ number of responding pharmacists and general practitioners. $P$-value: chi-square analysis of differences between the responses of pharmacists and general practitioners who answered that the content provides insufficient information

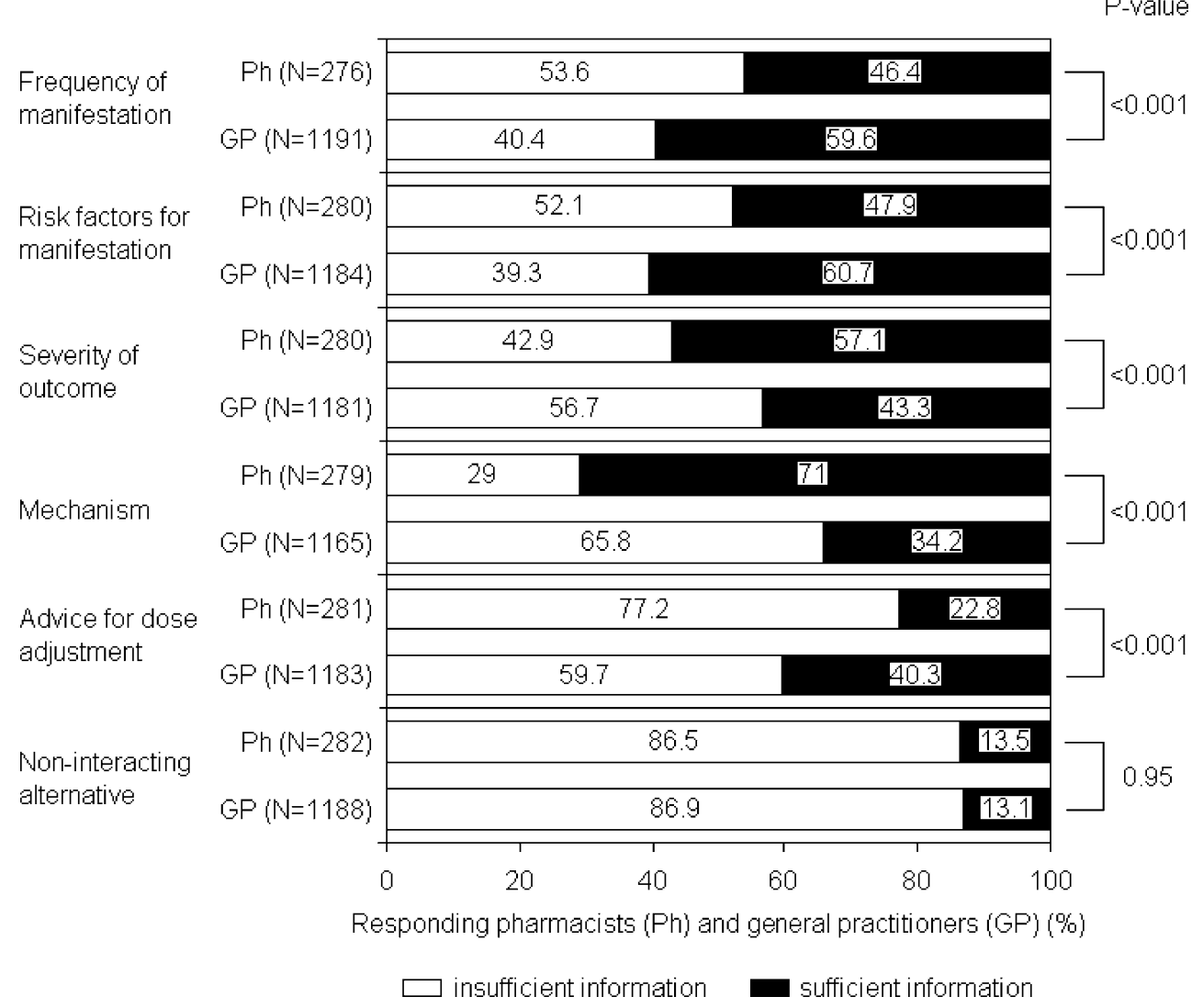

insufficient information

P-value 
Fig. 2 Swiss pharmacists' and German general practitioners' expectations with respect to the content of future drug-interaction information sources. Comparison of the results of two questionnaire surveys in 287 pharmacists and 1216 general practitioners by chi-square analysis. $N=$ number of responding pharmacists and general practitioners. $P$-value: chi-square analysis of differences between the responses of pharmacists and general practitioners who expected that the content is essential

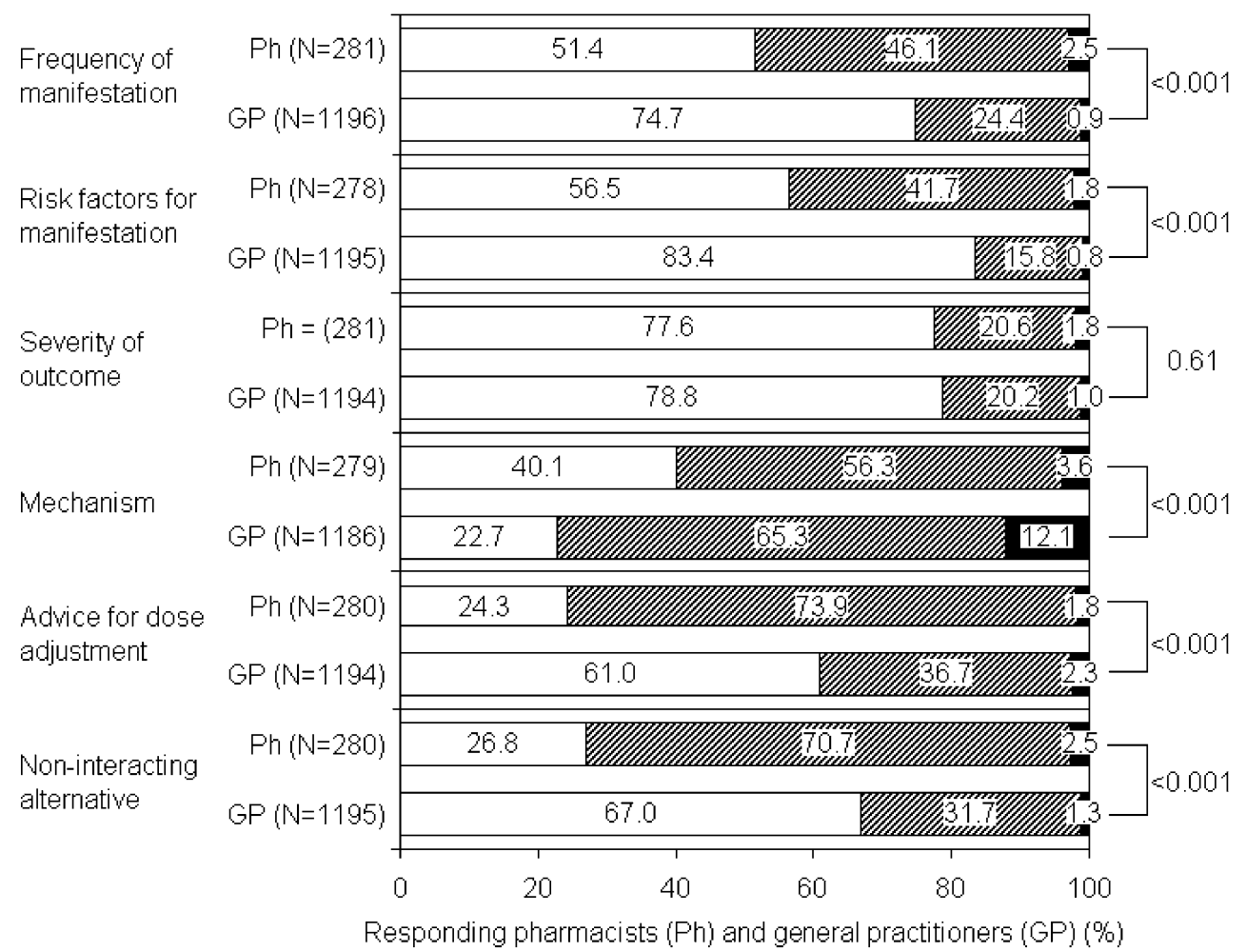

essential $\mathbb{Z}$ desirable, but not absolutely necessary dispensable of the outcome to be essential information, but all other comparisons of pharmacists' and general practitioners' satisfaction and future expectations differed significantly $(p<0.001)$ (Figs. 1 and 2).

Communication between pharmacists and prescribing physicians concerning potential drug interactions

Pharmacists reported a median of 25 (IQR 10-30) overall contacts to prescribing physicians, and a median of 3 (IQR 1-6) due to potential drug interactions during the 3 months preceding the survey. A total of $56.8 \%$ (163/287) pharmacists reported that they contacted physicians in general exclusively by telephone, the remaining $43.2 \%(124 / 287)$ that they did so by telephone or fax, video conferencing, email, mail, or via the patient. If the contact was induced by a potential drug interaction, most of the pharmacists $(72.5 \%, 208 / 287)$ chose direct communication by telephone.

Pharmacists' perception of the frequency of reasons for contacting a physician is presented in Fig. 3. The majority of pharmacists $(62.7 \%$; 180/282) reported that they contacted physicians "rarely" or "never" as a result of potential drug interactions. Pharmacists working in pharmacies whose drug-interaction surveillance software is configured to flag only "severe" potential drug interactions reported similar frequencies $(72.9 \%$; 35/48) for contacting a physi- cian "never" or "rarely" compared with the other pharmacists $(61.2 \% ; 126 / 208)(p=0.128)$.

\section{Discussion}

The use of computer software for prospective medication surveillance is a very common approach to avoiding medication errors [1]. In our study, all community pharmacies were equipped with drug-interaction surveillance software, and most of them (90.2\%) used it to identify potential drug interactions. Electronic drug-interaction checks in community pharmacies and physicians' offices can reduce the dispensing of prescriptions with severe interactions up to $67.5 \%$ [23]. Although immediate impact on prescription and dispensing has been demonstrated, there is only limited and inconclusive evidence as to whether the computer software is effective enough to prevent medication errors [24-26]. Evaluation of the performance of pharmacies' electronic drug-interaction systems in the USA showed that they largely varied in their ability in terms of specificity and sensitivity to identify clinically important potential drug interactions in daily practice [27].

In our survey, pharmacists reported that they considered $86 \%$ of interaction alerts, and thus admit to in fact ignoring 
Fig. 3 Reasons to contact a physician as indicated by 287 Swiss pharmacists in a questionnaire survey

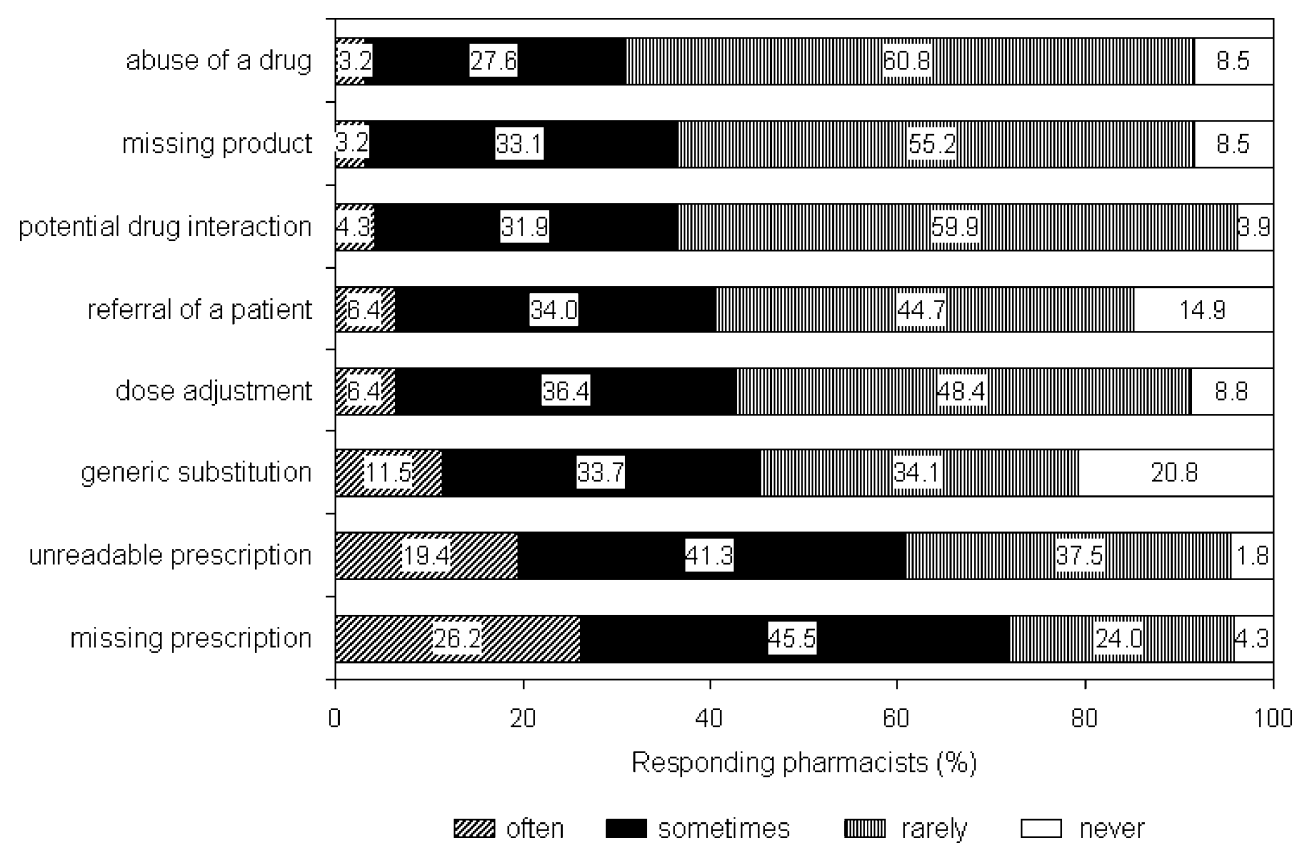

many drug interactions are concentration-dependent, and can be avoided by appropriately adjusting doses [12], optimized drug-interaction systems should also include an alert suppression if an interacting combination is prescribed in adjusted doses. Hence, more sophisticated filters instead of unjustified filters to flag only potential drug interaction of highest severity are needed. Indeed, Peng and coworkers [33] reported that sophisticated filters (assessment of overlapping time of drug therapies, of duration of drug therapy, and of total drug dose) could reduce the incidence of potential drug-interaction alerts by $71 \%$ and-in combination with clinical pharmacists' review-even by $94 \%$. Consequently, software providers should be challenged to revise and optimise the current drug-interaction surveillance software, and also include an alerting history in their software, because many alerts are caused by alreadychecked repeat prescriptions, and therefore are probably overridden [29, 30, 34].

Pharmacists most frequently sought information on drug interactions in their electronic surveillance system, even though it did not meet their expectations in most important aspects. In paticular, most pharmacists complained about a lack of information about non-interacting alternative therapies and the specific advice for dose adjustment. General practitioners expressed the same criticism [16]. In agreement, Hansten et al. [27, 31] noticed that management guidelines provided by drug interaction information sources are often inadequate, and should be considered in the classification of potential drug interactions.

With regard to the content of future drug-interaction information sources, community pharmacists and general practitioners expressed very different expectations, with the interaction software in more detail. Moreover, because 
largest difference seen in the evaluation of information components on advice for dose adjustment and noninteracting alternatives, which were less essential for community pharmacists. This result reflects the different situations and needs of the two professions in daily practice.

In comparison with further reasons to contact a physician, potential drug interactions play an inferior role (Fig. 2). The relatively low frequency of contacts (one per month), with respect to the high frequency of alerts and the statement that the majority of their patients are informed about the detected drug interactions, indicates that, in the process of prescribing and dispensing, community pharmacies mainly manage drug interaction alerts themselves. This raises the question of the relevance and quality of this management.

Some limitations of this survey merit discussion. First, the overall response rate was only $57.4 \%$, making a nonresponse bias possible. However, this figure compares well with a recent survey of German general practitioners [16] and the fact that non-responding pharmacists did not differ from responders suggests that such a bias will not be critical. Second, our study was conducted in the Germanspeaking part of Switzerland, and represents the health care situation in this region in the year 2005. However, there are many reasons justifying extrapolation of its results to other European health care systems. Indeed, drug-interaction software in community pharmacies from all German speaking countries (Switzerland, Germany, and Austria) is based on the same drug-interaction database, and in these countries many of the software systems used by the physicians have also integrated this database. Because of the numerous similarities in drug prescription and dispensing in Switzerland and Germany, it appears likely that the differences observed between the two professions rather relate to differences in their tasks and needs than differences between countries. It therefore supports the notion that specific tools should be developed for each profession.

In conclusion, our study revealed that the drug-interaction software supporting community pharmacists lacks sensitivity and specificity, while producing a high rate of "false" alerts. The study also showed that the information needs of community pharmacies differed considerably from those of general practitioners. Hence, substantial improvement of drug-interaction software systems is required in two at least important aspects - the suppression of inappropriate alerts and the tailoring to the needs of the user.

Acknowledgment The authors would like to thank the Swiss community pharmacists for their participation in this study.

\section{References}

1. Becker ML, Kallewaard M, Caspers PW, Schalekamp T, Stricker BH (2005) Potential determinants of drug-drug interaction associated dispensing in community pharmacies. Drug Saf 28:371-378

2. Jankel CA, Fitterman LK (1993) Epidemiology of drug-drug interactions as a cause of hospital admissions. Drug Saf 9:51-59

3. Gandhi TK, Weingart SN, Borus J, Seger AC, Peterson J, Burdick E et al (2003) Adverse drug events in ambulatory care. N Engl J Med 348:1556-1564

4. Gurwitz JH, Field TS, Harrold LR, Rothschild J, Debellis K, Seger AC et al (2003) Incidence and preventability of adverse drug events among older persons in the ambulatory setting. Jama 289:1107-1116

5. Jankel CA, Speedie SM (1990) Detecting drug interactions: a review of the literature. DICP 24:982-989

6. Bjorkman IK, Fastbom J, Schmidt IK, Bernsten CB (2002) Drugdrug interactions in the elderly. Ann Pharmacother 36:1675-1681

7. Costa AJ (1991) Potential drug interactions in an ambulatory geriatric population. Fam Pract 8:234-236

8. Bergendal L, Friberg A, Schaffrath A (1995) Potential drug-drug interactions in 5,125 mostly elderly out-patients in Gothenburg, Sweden. Pharm World Sci 17:152-157

9. Rosholm JU, Bjerrum L, Hallas J, Worm J, Gram LF (1998) Polypharmacy and the risk of drug-drug interactions among Danish elderly. A prescription database study. Dan Med Bull 45:210-213

10. Bjerrum L, Andersen M, Petersen G, Kragstrup J (2003) Exposure to potential drug interactions in primary health care. Scand J Prim Health Care 21:153-158

11. Linnarsson R (1993) Drug interactions in primary health care. A retrospective database study and its implications for the design of a computerized decision support system. Scand J Prim Health Care 11:181-186

12. Bergk V, Gasse C, Rothenbacher D, Loew M, Brenner H, Haefeli WE (2004) Drug interactions in primary care: impact of a new algorithm on risk determination. Clin Pharmacol Ther 76:85-96

13. McDonnell PJ, Jacobs MR (2002) Hospital admissions resulting from preventable adverse drug reactions. Ann Pharmacother 36:1331-1336

14. Huic M, Mucolic V, Vrhovac B, Francetic I, Bakran I, Giljanovic S (1994) Adverse drug reactions resulting in hospital admission. Int J Clin Pharmacol Ther 32:675-682

15. Raschetti R, Morgutti M, Menniti-Ippolito F, Belisari A, Rossignoli A, Longhini P et al (1999) Suspected adverse drug events requiring emergency department visits or hospital admissions. Eur J Clin Pharmacol 54:959-963

16. Bergk V, Gasse C, Schnell R, Haefeli WE (2004) Requirements for a successful implementation of drug interaction information systems in general practice: results of a questionnaire survey in Germany. Eur J Clin Pharmacol 60:595-602

17. Interpharma (2005) Das Gesundheitswesen in der SchweizLeistungen, Kosten, Preise. Available at: URL: http://www. interpharma.ch

18. ABDATA Pharma-Daten-Service (2005) ABDA-Datenbank. Werbe- und Vertriebsgesellschaft Deutscher Apotheker mbH, Eschborn, Germany

19. E-mediat AG (2005) Pharmavista, Schönbühl, Switzerland

20. Bergk V, Gasse C, Schnell R, Haefeli WE (2005) Mail surveys: obsolescent model or valuable instrument in general practice research? Swiss Med Wkly 135:189-191 
21. Jorgensen CK, Karlsmose B (1998) Validation of automated forms processing. A comparison of Teleform with manual data entry. Comput Biol Med 28:659-667

22. Morant J (2005) Arzneimittelkompendium der Schweiz. Documed AG, Basel

23. Halkin H, Katzir I, Kurman I, Jan J, Malkin BB (2001) Preventing drug interactions by online prescription screening in community pharmacies and medical practices. Clin Pharmacol Ther 69:260 265

24. Chrischilles EA, Fulda TR, Byrns PJ, Winckler SC, Rupp MT, Chui MA (2002) The role of pharmacy computer systems in preventing medication errors. J Am Pharm Assoc (Wash) 42:439-448

25. Soumerai SB, Lipton HL (1995) Computer-based drug-utilization review-risk, benefit, or boondoggle? N Engl J Med 332:1641-1645

26. Schulman KA, Rubenstein LE, Abernethy DR, Seils DM, Sulmasy DP (1996) The effect of pharmaceutical benefits managers: is it being evaluated? Ann Intern Med 124:906-913

27. Hansten PD, Horn JR, Hazlet TK (2001) ORCA: OpeRational ClassificAtion of drug interactions. J Am Pharm Assoc (Wash) 41:161-165
28. Magnus D, Rodgers S, Avery AJ (2002) GPs' views on computerized drug interaction alerts: questionnaire survey. J Clin Pharm Ther 27:377-382

29. Weingart SN, Toth M, Sands DZ, Aronson MD, Davis RB, Phillips RS (2003) Physicians' decisions to override computerized drug alerts in primary care. Arch Intern Med 163:2625-2631

30. Chui MA, Rupp MT (2000) Evaluation of online prospective DUR programs in community pharmacy practice. J Manag Care Pharm 6:200-204

31. Hansten PD (2003) Drug interaction management. Pharm World Sci 25:94-97

32. Durieux P (2005) Electronic medical alerts-so simple, so complex. N Engl J Med 352:1034-1036

33. Peng CC, Glassman PA, Marks IR, Fowler C, Castiglione B, Good CB (2003) Retrospective drug utilization review: incidence of clinically relevant potential drug-drug interactions in a large ambulatory population. J Manag Care Pharm 9:513-522

34. Murphy JE, Forrey RA, Desiraju U (2004) Community pharmacists' responses to drug-drug interaction alerts. Am J Health Syst Pharm 61:1484-1487 